This is an electronic reprint of the original article. This reprint may differ from the original in pagination and typographic detail.

Author(s): Fadjukoff, Päivi; Kroger, Jane

Title: Identity Development in Adulthood : Introduction

Year: $\quad 2016$

Version:

Please cite the original version:

Fadjukoff, P., \& Kroger, J. (2016). Identity Development in Adulthood : Introduction. Identity: An International Journal of Theory and Research, 16(1), 1-7. https://doi.org/10.1080/15283488.2015.1121821

All material supplied via JYX is protected by copyright and other intellectual property rights, and duplication or sale of all or part of any of the repository collections is not permitted, except that material may be duplicated by you for your research use or educational purposes in electronic or print form. You must obtain permission for any other use. Electronic or print copies may not be offered, whether for sale or otherwise to anyone who is not an authorised user. 


\title{
Identity Development in Adulthood: Introduction
}

\author{
Päivi Fadjukoffa and Jane Kroger \\ ${ }^{a}$ Agora Center, University of Jyväskylä, Jyväskylä, Finland; ' $P$ sychology Department, University of Tromsø, Tromsø, \\ Norway
}

\begin{abstract}
In line with Erikson's suggestions, increasing empirical evidence substantiates that considerable identity development takes place over the course of adulthood. What then does identity development during adulthood entail? The key findings of adult identity formation from four culturally different countries, and the challenges of analyzing the complex concept of identity are discussed. Although a wide array of identity measures are available, they have not been sufficiently validated for use with middle-aged or older adults. Additionally, different measures may yield results that are not comparable across studies. More studies are needed on adult identity development in populations representing different ethnicities and living in different cultural environments.
\end{abstract}

\section{KEYWORDS}

Adulthood; cross-cultural; identity development; identity measures

During his later professional years, Erik Erikson turned his attention to issues of identity and personality development in adulthood. He conceptualized identity as a partly conscious, partly unconscious sense of who one is and where one "fits" in the world. Identity is one's "Motiv des Forchens-what makes you move" (Erikson, 1979, Item 1602). Identity is what gives one's life purpose and meaning, within various social contexts. Although Erikson wrote extensively on the normative course and contents of an initial identity formation process during adolescence, particularly in the realms of vocational and ideological values and sexuality (e.g. Erikson, 1963, 1968), his thoughts on how identity might evolve over the course of adulthood were not as firmly delineated (Erikson, 1978; Erikson, Erikson, \& Kivnick, 1986). Erikson $(1963,1968)$ certainly did not view identity as a static entity that remains fixed once initial resolutions are made. He acknowledged that after initial identity commitments in adolescence, changing life circumstances, coupled with changing biological and psychological needs, were likely to spur ongoing identity developments over the course of the adulthood years.

Some of Erikson's speculations on identity development during adulthood can be found in his unpublished manuscripts and conference notes held by Harvard University's Houghton Library. In these notes, he raised questions of the ways by which identity may continue to evolve through the various crises of adulthood (Erikson, 1979). He also mused on what the potentialities for identity development in adulthood might be without the cultural constraints that exist for so many adults in various contexts around the world (Erikson, n.d.-a). Erikson also began to write about the integrative function that identity may serve for ongoing development during adulthood (Erikson, n.d.-b). Perhaps, however, his most succinct statement about the relationship between identity and adulthood came in his comment: "It is a sense of identity that presides over adulthood" (Erikson, 1983). It is the way in which that sense of identity presides over adulthood across a number of different cultural contexts that provides the inspiration for this Special Issue.

Empirically, patterns of identity development during adolescence and young adulthood have been well documented by researchers (e.g., Kroger, Martinussen, \& Marcia, 2010), and many of identity's dimensions during adolescence have been examined empirically across a number of cultural contexts (see Marcia, Waterman, Matteson, Archer, \& Orlofsky, 2011, for a review). However, ongoing 
identity development during adulthood has received far less consideration. In addition to Erikson, some have spoken theoretically about what will likely spur ongoing identity developments over the course of adulthood years (Bosma \& Kunnen, 2001; Kroger, 2003; Kunnen, 2006; Marcia, 2002). Empirically, internal issues such as readiness for change and internal conflict (Anthis \& La Voie, 2006; Kroger, 2003; Kunnen, 2006) and external issues such as individual critical life events, historical forces, the move to a new context, and influence of a significant other (Anthis, 2002a, 2002b; Fadjukoff, Kokko, \& Pulkkinen, 2010; Kroger \& Green, 1996; Kunnen \& Wassink, 2003; Luyckx, Goossens, \& Soenens, 2006) have been associated with identity changes during late adolescent and adult life.

Research has also indicated that identity achievement during adolescence and early adulthood remains elusive for many. From the meta-analytic work of Kroger et al. (2010), for example, only about one third of participants were rated identity achieved between age 21 and 29 and a little less than one half were rated identity achieved by age 30-36, based on results from cross-sectional studies. From a narrative review, the vast majority (some 8 of 10) longitudinal studies conducted primarily over the 18-22 age range, approximately one third to two thirds of young adults had not, nor were in the process of, constructing their own adult identities (Kroger, 2007). And so it appears that considerable scope for identity development does exist over the course of adulthood.

\section{Questions regarding identity development across adulthood}

A number of questions regarding the ongoing course of identity development over adulthood arise from Erikson's unpublished notes and previous theoretical and empirical suggestions.

(1) What does identity during the adulthood years entail? What dimensions of identity change and what remain stable over the course of adulthood? What are factors that may precipitate identity change or be associated with identity stability? How does identity shape responses to the Eriksonian psychosocial tasks of adult development: intimacy versus isolation, generativity versus stagnation, integrity versus despair? And how do these developmental tasks of adulthood shape the course and contents of identity over time?

(2) If identity achievement is not obtained by entry into young adulthood, what is the likelihood that it will be obtained during the adulthood years?

(3) What are common identity trajectories or cycles of identity development during adulthood once initial identity-defining decisions have taken place, and what circumstances are associated with these trajectories?

(4) Are there cultural variations in the process of identity development through adulthood? If so, are there particular socialization forces within and across cultural contexts that are associated with particular patterns of identity stability and change?

The studies included in this Special Issue begin to address some of these questions.

\section{International perspectives on identity}

Erikson's writings on identity have been inspired by Western cultures in which commitments can be based on individual exploration and choice rather than duty and obligation, as noted by Côté and Levine (2002). In Western societies, active identity formation strategies have become increasingly important as the societies have evolved from industrialized to late modern age, characterized by individualization, relativity of values, and restructuring of social systems. Following Erikson and Marcia (1966), the majority of identity research has been carried out in the United States and Canada. Even though international issues were emphasized when establishing Identity: An International Journal of Theory and Research, the dominance of northern America in the journal publications as well as participation in the Society for Research on Identity Formation has increased 
Table 1. The number of empirical research articles published in Identity: An International Journal of Theory and Research by geographical area

\begin{tabular}{|c|c|c|c|c|c|c|c|c|}
\hline & \multicolumn{2}{|c|}{ 2001-2005 } & \multicolumn{2}{|c|}{ 2006-2010 } & \multicolumn{2}{|c|}{ 2011-2014 } & \multicolumn{2}{|c|}{ Total } \\
\hline & $\mathrm{N}$ & $\%$ & $\mathrm{~N}$ & $\%$ & $\mathrm{~N}$ & $\%$ & $\mathrm{~N}$ & $\%$ \\
\hline United States \& Canada & 37 & 56 & 44 & 64 & 41 & 72 & 122 & 64 \\
\hline Europe & 9 & 14 & 12 & 17 & 11 & 19 & 32 & 17 \\
\hline Middle East & 3 & 5 & 4 & 6 & 2 & 4 & 9 & 5 \\
\hline Caribbean & 8 & 12 & 0 & 0 & 0 & 0 & 8 & 4 \\
\hline Australia \& New Zealand & 3 & 5 & 1 & 1 & 0 & 0 & 4 & 2 \\
\hline Africa & 3 & 5 & 1 & 1 & 0 & 0 & 4 & 2 \\
\hline East Asia & 0 & 0 & 3 & 4 & 1 & 2 & 4 & 2 \\
\hline Several continents & 3 & 5 & 4 & 6 & 2 & 4 & 9 & 5 \\
\hline Total & 66 & 100 & 69 & 100 & 57 & 100 & 192 & 100 \\
\hline
\end{tabular}

during the years. This is clearly seen in the numbers of published empirical research articles across years by continent, as presented in Table 1 .

Ethnic and racial identity has been one of the main focuses of published identity research. As cultures vary and historical times vary in their socialization practices, cross-cultural research is indeed important for furthering our understanding of identity formation. Specifically in 2001-2003, three successive Identity Special Issues were dedicated to issues related to ethnic identities: "Diasporas and Transnational Identities," number 3 in 2001; "Diasporic Identity: Myth, Culture, and the Politics of Home," number 2 in 2002; and "Identity and Power in Africa and the Caribbean," number 1 in 2003. Additionally, many published articles discussed immigrant and other minority identities such as the Chinese American, African American, and biracial individuals in the United States; Jews in Belgium; East Indians in Canada; and Arabs in Israel. The ethnic background of subjects has been conscientiously reported. However, more studies are needed on identity development in majority populations representing different ethnicities and living in different cultural environments.

\section{Context for studies of this special issue}

The articles in this Special Issue present findings of adult identity formation from four culturally different countries: Finland, Sweden, Japan, and Trinidad. The developmental findings in three of the studies are based on longitudinal data, and in one study on the analysis of different age cohorts. To facilitate the understanding of the cultural environments of each study, we offer a short introduction to each country. This information is based on Encyclopedia.com (2015) and the World Factbook (2015) as well as material published by each country.

\section{Country introductions}

Finland and Sweden are neighboring Nordic welfare states and European Union members with advanced gender equality and economies that rate among the highest per capita incomes in the world. Historically, Sweden was a North European military power, with Finland being its eastern province behind the Gulf of Bothnia for 600 years before the province was lost to Russia in 1809 and later became independent in 1917. The majority of inhabitants of these countries belong to the Evangelical Lutheran Church, although religion nowadays plays a minor role in the everyday life of most inhabitants. In both countries, cohabitation is frequent and culturally accepted (Haagensen, 2014). For instance, in Finland, over $40 \%$ of children are born to unmarried parents (Statistics Finland, 2015). However, there are also many differences between these countries. According to Statistics Sweden (2015), almost 29\% of Sweden's nearly 10 million inhabitants have a partial foreign background (at least one of the parents foreign born) in 2014. Foreign-born immigrants compose $16 \%$ of the population, with two thirds arriving from countries outside of the European Union. In contrast to Sweden, Finland's population is homogeneous. As confirmed by Statistics Finland, only 
$5 \%$ of the population is of foreign origin. Reinforcing the indigenous culture, the Finnish language is one of the few languages spoken in Europe that does not belong to the Indo-European family of languages and is markedly different from them.

Situated on the Japanese archipelago off the eastern edge of the Asian continent, Japan is a country of ancient unique culture, developed from the Paleolithic era. Japan is a modern, highly technologically advanced economy that has the third-largest gross domestic product (GDP) in the world. It has nearly 130 million people, the 10th largest population in the world, predominantly living in the extremely densely populated cities. The population is homogeneous, with less than $2 \%$ of inhabitants of foreign origin. The Japanese language is indigenous and does not relate to other languages (although the written form is largely acquired from Chinese). Many Japanese maintain affiliations with both main religions, Shintoism (78\%) and Buddhism (66\%), but religion does not have a major role in most people's everyday lives (Japan Fact Sheet, 2015). The society has been strongly male dominated, and a law related to gender equal employment opportunities came into effect only in 1986. The support structures for working women are minimal and the birth rates are rather low. The population is aging: in 2013 approximately 25\% of the Japanese were age 65 or older (Japan Fact Sheet, 2015). The country is located in a volcanic zone and substantially prone to destructive earthquakes and tsunamis; Japan has the highest natural disaster risk in the developed world.

Trinidad and Tobago are tropical islands situated off the northern edge of South America, but considered part of the Caribbean. The republic of Trinidad and Tobago gained independence in 1962 after being colonized for 500 years mainly by Spain and Britain, but also by other colonizers. The majority of the 1.3 million inhabitants live on the island of Trinidad. The country is characterized as a high-income developing country (UNDAF, 2013). Although the number of older people is increasing, only $9 \%$ of the people were age 65 or older in 2011 (Central Statistical Office, 2011). Trinidad is highly industrialized and enjoys big oil and natural gas reserves whereas Tobago is dominated by tourism and agriculture. Due to a long history of colonization and immigration, the population is ethnically diverse, although each ethnic group largely retains its own culture. The major ethnic groups are Indo- (40\%) and Afro- (37\%) Trinidadians; mixed and other minor ethnic groups comprise about $20 \%$ of the population. Various religions are practiced freely, the largest groups being Roman Catholic, Protestant, and Hindu. Acknowledged challenges of the society are high rates of poverty, violence, and crime, and policies have been established for improvements (UNDAF, 2013).

\section{Key findings of the investigations}

The first article by Päivi Fadjukoff, Lea Pulkkinen, and Katja Kokko analyzes patterns of identity formation in five identity domains and overall identity in a representative sample from a cohort of Finnish men and women born in 1959; identity status was assessed at age 27, 36, 42, and 50, as part of the Jyväskylä Longitudinal Study of Personality and Social Development. Although developmental trends varied across domains, movement toward identity achievement was predominant. Gender differences emerged at all data collection times, and women typically reached achievement earlier than men. Identity diffusion was more typical and persistent in men, specifically in the ideological domains.

The second article by Maria Wängqvist, Johanna Carlsson, Maria van der Lee, and Ann Frisén focuses on identity development longitudinally in the area of romantic relationships. The study was based on a representative sample of Swedish men and women, assessed at age 25 and 29 and was part of the Gothenburg Longitudinal Study of Development. The study highlighted romantic relationships as an important identity domain, showing that attitudes and values concerning romantic relationships were salient identity issues during these years. The expressed attitudes and expectations of romantic relationships were based on compliance to social norms, especially strong for the foreclosure group. Additionally, young women typically reached identity achievement earlier than men, although the gender difference disappeared at age 29. There were wide variations in the individual identity change patterns, although stability from age 25 to 29 was the most typical trajectory. 
The third article by Toshiaki Shirai, Tomoyasu Nakamura, and Kumiko Katsuma explores, longitudinally, adult identity development dynamics in relation to time orientation for the past, present, and future in a Japanese sample from age 23 to 31 . Interestingly, the samples were assessed at frequent time intervals (yearly) during the course of this 11-year study, although the time intervals were grouped for analysis into 3- or 4-year blocks. The results confirmed the importance of future orientation, optimistic views, and delay of gratification for developing identity commitments in emerging adulthood whereas identity exploration was positively associated with concerns related to the future and present-oriented attitudes, but also with delay of gratification. In this study, no gender differences emerged. The results showed no age differences in identity commitment or crisis, but a decrease in identity exploration with age.

The fourth article by Mary Jane Arneaud, Nicole Alea, and Makayla Espinet analyzes identity status differences in Trinidad in five age groups: adolescence and emerging adulthood as well as young, middle, and older adulthood. Trinidad's major ethnic groups were proportionally represented in the sample. Identity achievement was found to characterize middle age, and it was associated with being married and having children. Moratorium and diffusion identity statuses were typical for emerging and young adults and were related to unemployment.

These studies provide a picture of identity trajectories during adulthood, emphasizing variability. Each study identifies how one or more of identity's many dimensions remain stable as well as change over time. Fadjukoff et al. and Arneaud et al. refer to a progressive trend of identity development whereby identity achievement typically increased in middle age as compared to early adulthood. However, Wängqvist et al. and Shirai et al., studying age groups up to age 30, found identity status stability to be most typical. This implies that significant identity development may typically take place during and after early adulthood. Identity exploration, however, was typical at earlier ages and in unstable life circumstances as found by Shirai et al. and Arneaud et al. Results from these investigations support the concept of emerging adulthood as a prolonged stage of psychosocial moratorium and self-exploration (Arnett, 2000).

The studies also provide interesting insights into gender and identity. Fadjukoff et al. and Wängqvist et al. found that women typically progressed to identity achievement earlier than men, based on studies of participants in the general population. However, Shirai et al. did not find differences between men and women among their participants who were drawn from a specific field of study and were mainly primary school teachers in training. These differences in findings suggest that, although there may be gender differences in the general population, men and women in specific population subgroups may follow more similar, nongendered identity status distribution patterns.

The selection of studies in this Special Issue highlights some of the challenges in identity research across various cultures and ages. A wide array of identity measures exists, and different measures may yield results that are not comparable across studies. Two of the studies used Marcia's (1966) semistructured Identity Status Interviews. Fadjukoff et al. reported results based on five domains, and Wängqvist et al. reported results in the domain of romantic relationships alone. Two studies were based on self-report measures: Shirai et al. utilized the Japanese Identity Status Scale (ISS; Kato, 1983) and Arneaud et al. used the UtrechtManagement of Identity Commitments Scale (U-MICS; Crocetti, Rubini, \& Meeus, 2008). The ISS is a general overall identity scale whereas the U-MICS is based on three individually selected domains out of nine. These measures have slightly different perspectives on identity development and different criteria for assessment. Therefore, although identity foreclosure was found frequently in the studies conducted in Finland and Sweden and was nonexistent in Trinidad, this finding is more likely to reflect differences in the methods used to assess identity status rather than in the culture itself.

Each type of measure brings different challenges in analyzing the complex concept of identity. These and other identity measures have been developed for adolescent studies, and their validation for use with middle-aged or older adults is insufficient. There might also be difficult conceptual challenges in utilizing self-report questionnaires longitudinally because the questions might not be appropriate for each age group. On the other hand, it is difficult to collect large datasets using interviews. Additionally, qualitative or nominal scale measures bring limitations to the statistical techniques that can be utilized in assessment. Development and validation of identity measures 
across ages and various cultural contexts will be needed in future identity research. Specifically, methodologies that enable really long-term studies with relatively frequent data collection points will be required.

\section{Future identity research during adulthood in cross-cultural contexts}

Earlier in this Introduction, we raised a number of questions about identity development over the course of adulthood, based on theoretical and empirical work by Erikson and others. Basic to all questions, however, is: What does identity development during adulthood entail? This question was asked informally to late-life research participants in a pilot study by the second author, and the following responses were typical: "Letting go of the identity that one has worked so long and hard to develop"; "Cultivating the letting go of having to be a certain thing or way"; "Holding life more lightly"; "Letting go of the irritating search for certainty"; "Realizing that nothing is solid"; "Appreciating more strongly that this isn't going to go on forever, and that needs to be taken into account in how I'm going to live my life now." In our future endeavors to understand identity development during adulthood, narrative studies that allow participants to articulate what identity means to them at particular ages or life stages will be key to future meaningful identity theory development and research. Narrative studies, such as that by Stewart, Winter, D. Henderson-King, and Henderson-King (2015), that aim to understand the relationship between identity development and context through various phases of adulthood from the participant's perspective are an important step in this direction.

In addition to studies undertaking comparative identity work across multiple cultural settings, a research focus on identity in the years of late adulthood is needed. Comparative identity studies involving multiple cultural contexts should eventually enable generalizations about common socialization forces and associated identity positions or patterns of change. Such generalizations will highlight, more clearly, commonalities across cultures that appear to promote or impede identity revision and maintenance processes across the adult life span. The years of late adulthood as a focus for identity research have received little attention in the research literature, let alone in terms of cross-national and cross-cultural comparative work. Political, social, and economic circumstances differ across cultural settings, in terms of societal attitudes toward and state provisions for older adults. These contextual differences likely will have enormous implications on identity consolidation and feelings of well-being in later life and provide a fertile ground for future research.

We hope that this Special Issue serves as a trigger to further research on cultural variations and similarities in the process of identity development through adulthood.

\section{References}

Anthis, K. S. (2002a). On the calamity theory of growth: The relationship between stressful life events and changes in identity over time. Identity: An International Journal of Theory and Research, 2, 229-240. doi:10.1207/ S1532706XID0203_03

Anthis, K. S. (2002b). The role of sexist discrimination in adult women's identity development. Sex Roles, 47, 477-484. doi:10.1023/A:1021604611766

Anthis, K. S., \& La Voie, J. C. (2006). Readiness to change: A longitudinal study of changes in adult identity. Journal of Research in Personality, 40, 209-219. doi:10.1016/j.jrp.2004.12.004

Arnett, J. J. (2000). Emerging adulthood: A theory of development from the late teens through the twenties. American Psychologist, 55, 469-480. doi:10.1037/0003-066X.55.5.469

Bosma, H., \& Kunnen, E. S. (2001). Determinants and mechanisms in ego identity development: A review and synthesis. Developmental Review, 21, 39-66. doi:10.1006/drev.2000.0514

Central Statistical Office. (2011). Trinidad \& Tobago 2011 population and housing census demographic report. Retrieved from http://www.planning.gov.tt/sites/default/files/content/mediacentre/documents/Trinidad-and-TobagoDemographic-Report-2011.pdf 
Côté, J. E., \& Levine, C. G. (2002). Identity formation, agency, and culture: A social psychological synthesis. Mahwah, NJ: Erlbaum.

Crocetti, E., Rubini, M., \& Meeus, W. (2008). Capturing the dynamics of identity formation in various ethnic groups: Development and validation of a three-dimensional model. Journal of Adolescence, 31, 207-222. doi:10.1016/j. adolescence.2007.09.002

Encyclopedia.com. (2015). [Finland], [Sweden], [Trinidad and Tobago]. London, United Kingdom: Cengage Learning. Retrieved from http://www.encyclopedia.com/

Erikson, E. H. (1963). Childhood and society (2nd ed.). New York, NY: Norton.

Erikson, E. H. (1968). Identity: Youth and crisis. New York, NY: Norton.

Erikson, E. H. (Ed.). (1978). Adulthood. New York, NY: Norton.

Erikson, E. H. (1979). Lifecycle and the community. Julian Huxley source materials, Item 95 M-2, Erikson Harvard Papers. Harvard University, Cambridge, MA.

Erikson, E. H. (1983). Reflections. Item 1631, Erikson Harvard Papers. Harvard University, Cambridge, MA.

Erikson, E. H. (n.d.-a). Notes from planning conference on the adult. bMS AM 2031, Item 1516. Erikson Harvard Papers, Harvard University, Cambridge, MA.

Erikson, E. H. (n.d.-b). From Fragments. Item 1725. Erikson Harvard Papers, Harvard University, Cambridge, MA.

Erikson, E. H., Erikson, J. M., \& Kivnick, H. (1986). Vital involvement in old age. New York, NY: Norton.

Fadjukoff, P., Kokko, K., \& Pulkkinen, L. (2010). Changing economic conditions and identity formation in adulthood. European Psychologist, 15, 293-303. doi:10.1027/1016-9040/a000061

Haagensen, K. M. (Ed.). (2014). Nordic statistical yearbook 2014 (Vol. 52). Copenhagen, Denmark: Nordic Council of Ministers.

Japan Fact Sheet. (2015). Web Japan. Tokyo, Japan: Ministry of Foreign Affairs of Japan. Retrieved from http://webjapan.org/factsheet/index.html

Kato, A. (1983). Daigakusei ni okeru doitsusei no shoso to sono kozo [A study of identity statuses and their structure in university students]. Japanese Journal of Educational Psychology, 31, 292-302. doi:10.5926/jjep1953.31.4_292

Kroger, J. (2003). What transits in an identity status transition? Identity: An International Journal of Theory and Research, 3, 197-220. doi:10.1207/S1532706XID0303_02

Kroger, J. (2007). Why is identity achievement so elusive? Identity: An International Journal of Theory and Research, 7 , 331-348. doi:10.1080/15283480701600793

Kroger, J., \& Green, K. E. (1996). Events associated with identity status change. Journal of Adolescence, 19, 477-490. doi:10.1006/jado.1996.0045

Kroger, J., Martinussen, M., \& Marcia, J. E. (2010). Identity status change during adolescence and young adulthood: A meta-analysis. Journal of Adolescence, 33, 683-698. doi:10.1016/j.adolescence.2009.11.002

Kunnen, E. S. (2006). Are conflicts the motor in identity change? Identity: An International Journal of Theory and Research, 6, 169-186. doi:10.1207/s1532706xid0602_3

Kunnen, E. S., \& Wassink, M. E. K. (2003). An analysis of identity change in adulthood. Identity: An International Journal of theory and Research, 3, 347-366. doi:10.1207/S1532706XID0304_03

Luyckx, K., Goossens, L., \& Soenens, B. (2006). A developmental contextual perspective on identity construction in emerging adulthood: Change dynamics in commitment formation and commitment evaluation. Developmental Psychology, 42(2), 366-380. doi:10.1037/0012-1649.42.2.366

Marcia, J. E. (1966). Development and validation of ego-identity status. Journal of Personality and Social Psychology, 3, 551-558. doi:10.1037/h0023281

Marcia, J. E. (2002). Identity and psychosocial development in adulthood. Identity: An International Journal of Theory and Research, 2, 7-28. doi:10.1207/S1532706XID0201_02

Marcia, J. E., Waterman, A. S., Matteson, D. R., Archer, S. L., \& Orlofsky, J. L. (Eds.). (2011). Ego identity: A handbook for psychosocial research. New York, NY: Springer.

Statistics Finland. (2015). Population. Retrieved from http://www.stat.fi/til/vrm_en.html

Statistics Sweden. (2015). Persons by type of household, background and sex 31 December 2014. Retrieved from http://www.scb.se/en_/Finding-statistics/Statistics-by-subject-area/Population/Population-composition/ Population-statistics/

Stewart, A. J., Winter, D. G., Henderson-King, D., \& Henderson-King, E. (2015). How politics become personal: Sociohistorical events and their meanings in people's lives. Journal of Social Issues, 71, 294-308. doi:10.1111/ josi.2015.71.issue-2

The World Factbook. (2015). Center for the Study of Intelligence, USA. Retrieved from https://www.cia.gov/library/ publications/resources/the-world-factbook/

UNDAF. (2013). Drilling down development in Trinidad and Tobago. United Nations Development Assistance Framework, 2014-2015 Biennial rolling plan. United Nations and Republic of Trinidad and Tobago. Retrieved from http://www.undp.org.tt/infomation\%20disclosure\%20requirement/UNDAF\%20\%282014\%20-\%202015\%29\% 20-\%20Trinidad\%20\%26\%20Tobago\%20Final.pdf 